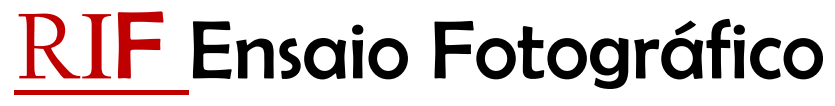

\section{Fé Canindé: sobre romeiros, romarias e ex-votos}

Fotos: Itamar de Morais Nobre ${ }^{1}$

Texto: Beatriz Lima de Paiva ${ }^{2}$

O ensaio fotográfico é um recorte de um projeto documental em desenvolvimento o qual aborda os romeiros $^{3}$, as romarias e os ex-votos ${ }^{4}$ praticados por devoção a São Francisco de Canindé, no município de Canindé, localizado a 110 km de distância da cidade de Fortaleza, capital do estado do Ceará (CE), situado na Região Nordeste do Brasil ${ }^{5}$. As fotografias foram capturadas durante a festa em homenagem ao santo, que ocorre anualmente entre os dias 24 de setembro a 04 de outubro ${ }^{6}$. No entanto, no ano de 2016, especialmente por causa das eleições, a festa se prorrogou para após o pleito. É uma iniciativa vinculada ao Grupo de Pesquisa ECOMSUL - Epistemologias e Práticas Emergentes e Transformadoras em Comunicação, Mídias e Cultura, do Departamento de Comunicação Social e Programa de Pós-graduação em Estudos da Mídia/UFRN.

Dentre as manifestações populares religiosas de mais evidência no município durante esse período festivo, tem-se a "romaria", constituída pela peregrinação de romeiros individual ou coletivamente para igrejas, santuários e túmulos de pessoas consideradas "santas" ou "milagrosas" visando o cumprimento de promessas, doações, entrega de ex-votos, dentre outros. Acerca do seu contexto histórico, a tradição chegou ao Brasil pelos portugueses e não consta nos registros documentais a incidência religiosa indígena, tampouco dos africanos

\footnotetext{
${ }^{1}$ Docente e pesquisador do Departamento de Comunicação Social (DECOM) e do Programa de PósGraduação em Estudos da Mídia (PPgEM), da Universidade Federal do Rio Grande do Norte (UFRN). Pesquisador do Grupo de Pesquisa ECOMSUL - Epistemologias e Práticas Emergentes e Transformadoras em Comunicação, Mídias e Cultura. Email: itanobre@gmail.com

${ }^{2}$ Mestranda pelo Programa de Pós-graduação em Estudos da Mídia (PPgEM/UFRN). Pesquisadora do Grupo de Pesquisa ECOMSUL - Epistemologias e Práticas Emergentes e Transformadoras em Comunicação, Mídias e Cultura Email: beatriz_lima2@hotmail.com

${ }^{3}$ Cascudo define o romeiro em: "devoto que integra a romaria para cumprir promessa, pedir ajuda ao santo de sua predileção e orar." (CASCUDO, 2001, p. 603).

${ }^{4}$ Ex-voto. Do latim votum, coisa prometida. "O que se promete deve ser pago", diz o ditado. Ex-voto é o que se promete ao santo de devoção para se receber a graça, ou o que se oferece por tê-la alcançado [...] Pode ser: vela, foto, flor, partes do corpo feitas em cera, barro ou madeira, e outros objetos [...]. (CASCUDO, 2001, p. 220, grifos do autor).

${ }^{5}$ Disponível em: < http://www.santuariodecaninde.com/caninde/ > Acesso em 09 jun. 2017

${ }^{6}$ Quando em período eleitoral, a data é alterada para o período de 04 a 14 de outubro, bem como ocorreu no ano de 2016, período no qual as fotografias que compõem este ensaio foram registradas.
} 


\section{RIF, Ponta Grossa/ PR Volume 15, Número 34, p.239-248, Janeiro/Junho 2017}

advindos como escravos, pois, somente aqueles que eram muçulmanos obtiveram contato com as romarias. (CASCUDO, 2001). Em se tratando do reconhecimento da tradicional peregrinação de Canindé, o autor ressalta que:

No Brasil os principais centros de romaria são: Nossa Senhora de Nazaré (Belém do Pará), São Francisco de Canindé (Canindé), Ceará, Bom Jesus do Bonfim (Itapagipe, cidade de Salvador, Bahia) Bom Jesus da Lapa (Pirapora, rio São Francisco), Nossa Senhora de Aparecida (Aparecida) e Bom Jesus de Pirapora, ambos em São Paulo[...]. (CASCUDO, 2001, p. 603, grifo nosso).

As contribuições de Beltrão na área da Folkcomunicação (1980) retratam os estudos dos agentes e meios populares de expressão de ideias. Nesse sentido, tendo em vista o reconhecimento da manifestação popular religiosa, pode-se identificar a existência de processos comunicacionais na peregrinação aqui apresentada. Corroborando desse pensamento, temos em Cascudo (2001, p. 602) que a romaria "é campo aberto ao estudo da etnografia e do folclore, de alto interesse humano".

Diante do exposto, compreende-se uma dimensão da proposta do fotodocumentário. No entanto, ele objetiva ainda experimentar o uso do dispositivo móvel digital e identificar quais as suas abordagens e peculiaridades para, através dessa experiência, reproduzir no ensino e pesquisa acadêmica o desenvolvimento de trabalhos utilizando o dispositivo móvel digital no registro de imagens fotográficas.

O trabalho tem desenvolvido a partir da Fotocartografia Sociocultural (Nobre, 2011 p. 59), um mapeamento simbólico que "auxilia a perceber e a reconstituir, no plano social, as ações políticas da sociedade civil e as atividades cotidianas desenvolvidas como modos de vida". Para a realização dos registros fotográficos utilizou-se o dispositivo móvel digital Nokia Lumia 1020.

O plano de atuação consiste em visitar periodicamente o município, por dois anos, a partir de 2016, e montar um banco de dados a fim de selecionar as fotografias de maior qualidade técnica para a divulgação em exposições e publicações em congressos e periódicos. 
Imagem 01 - Fé e contrição: a entrega de quem busca amparo na devoção.

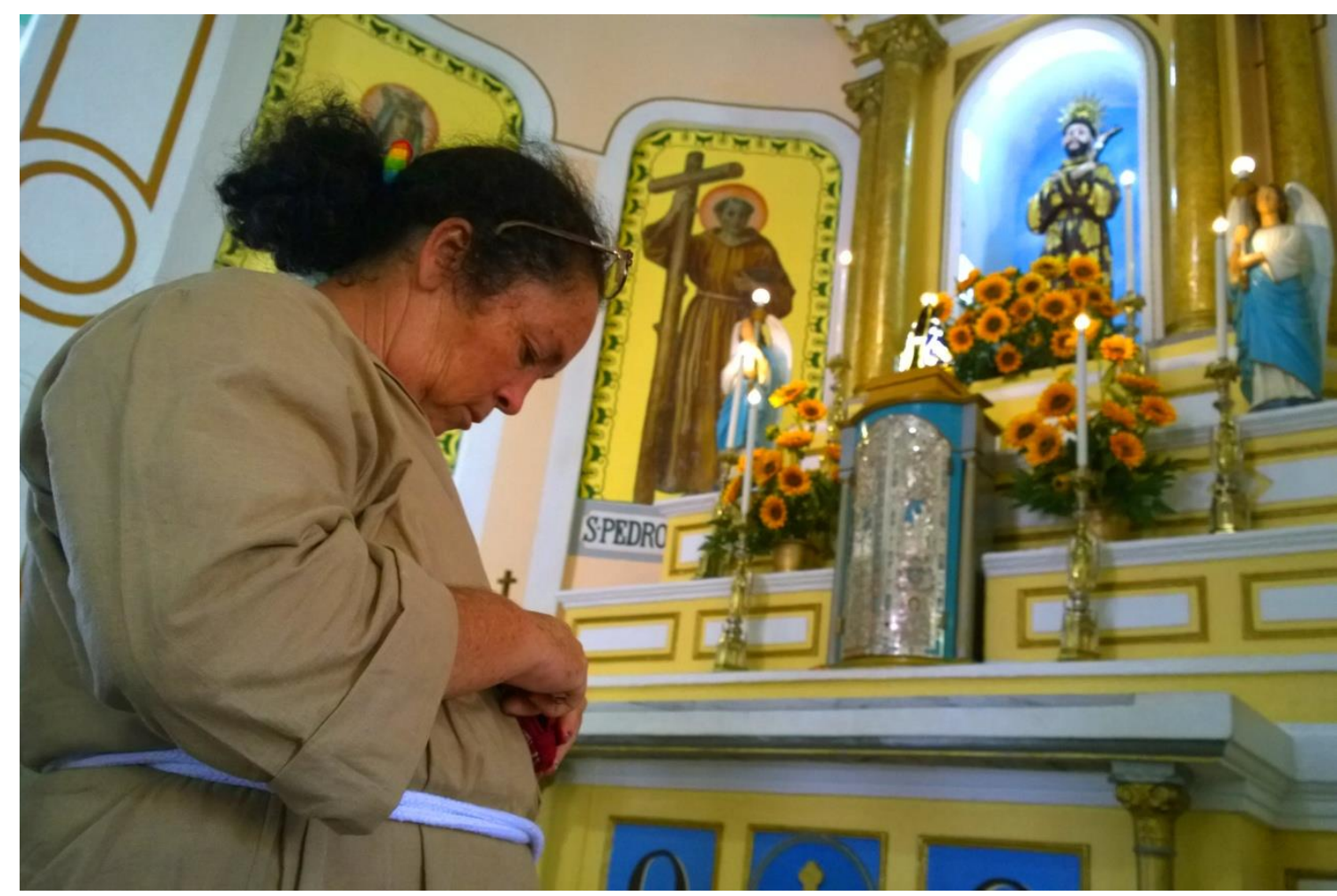

Imagem 02 - Só a fé diz o que vê

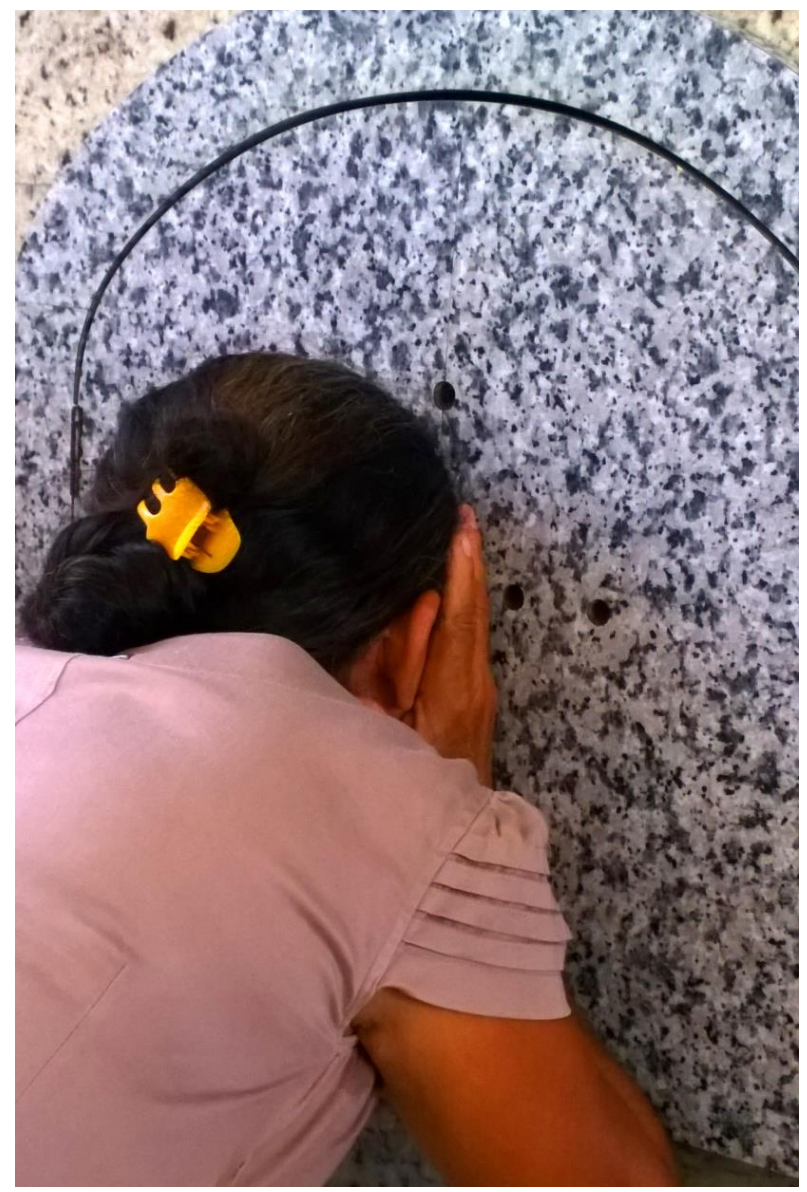




\section{Imagem 03 - As velas iluminam os caminhos das preces}

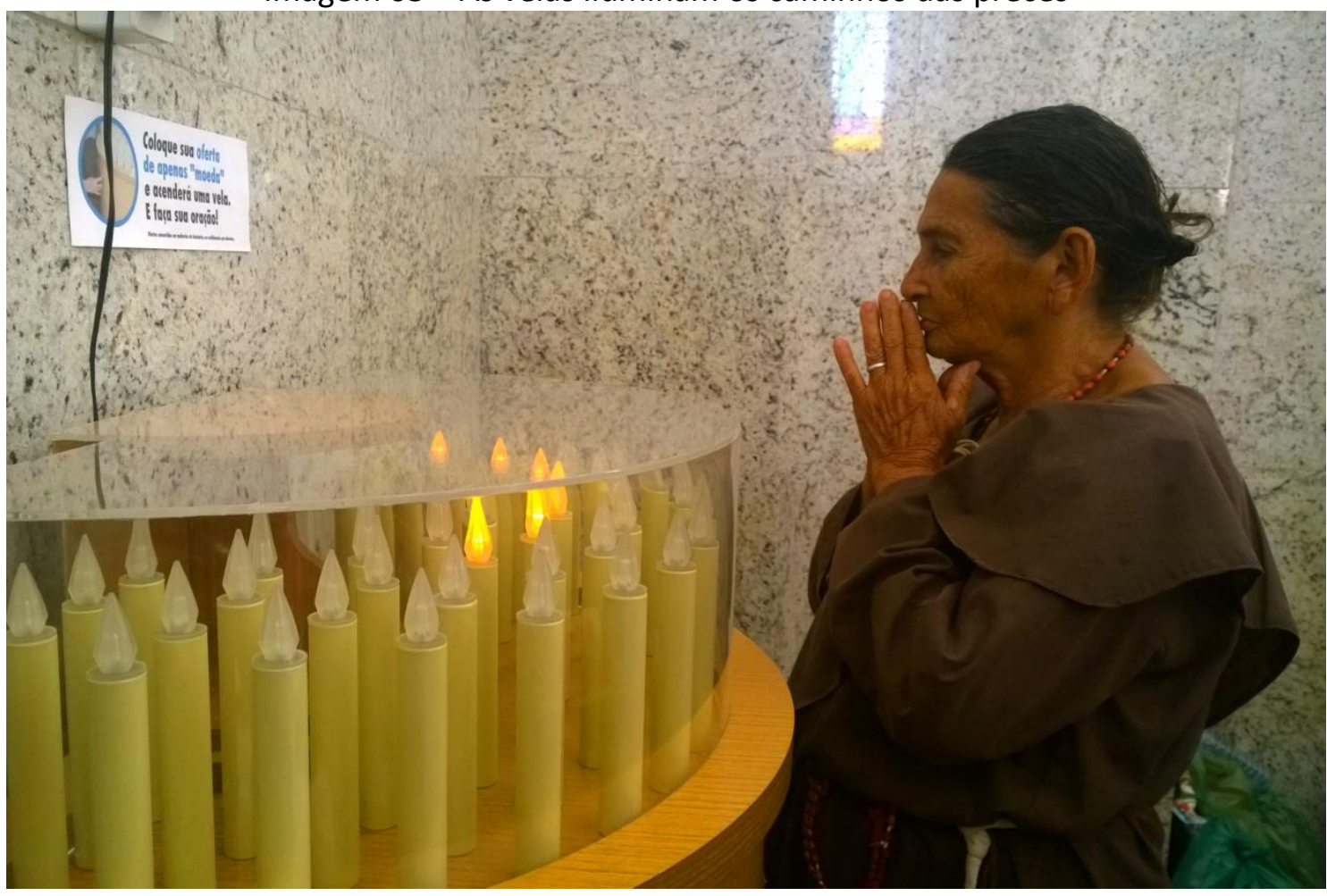

Imagem 04 - A fé: das mãos ao cordão

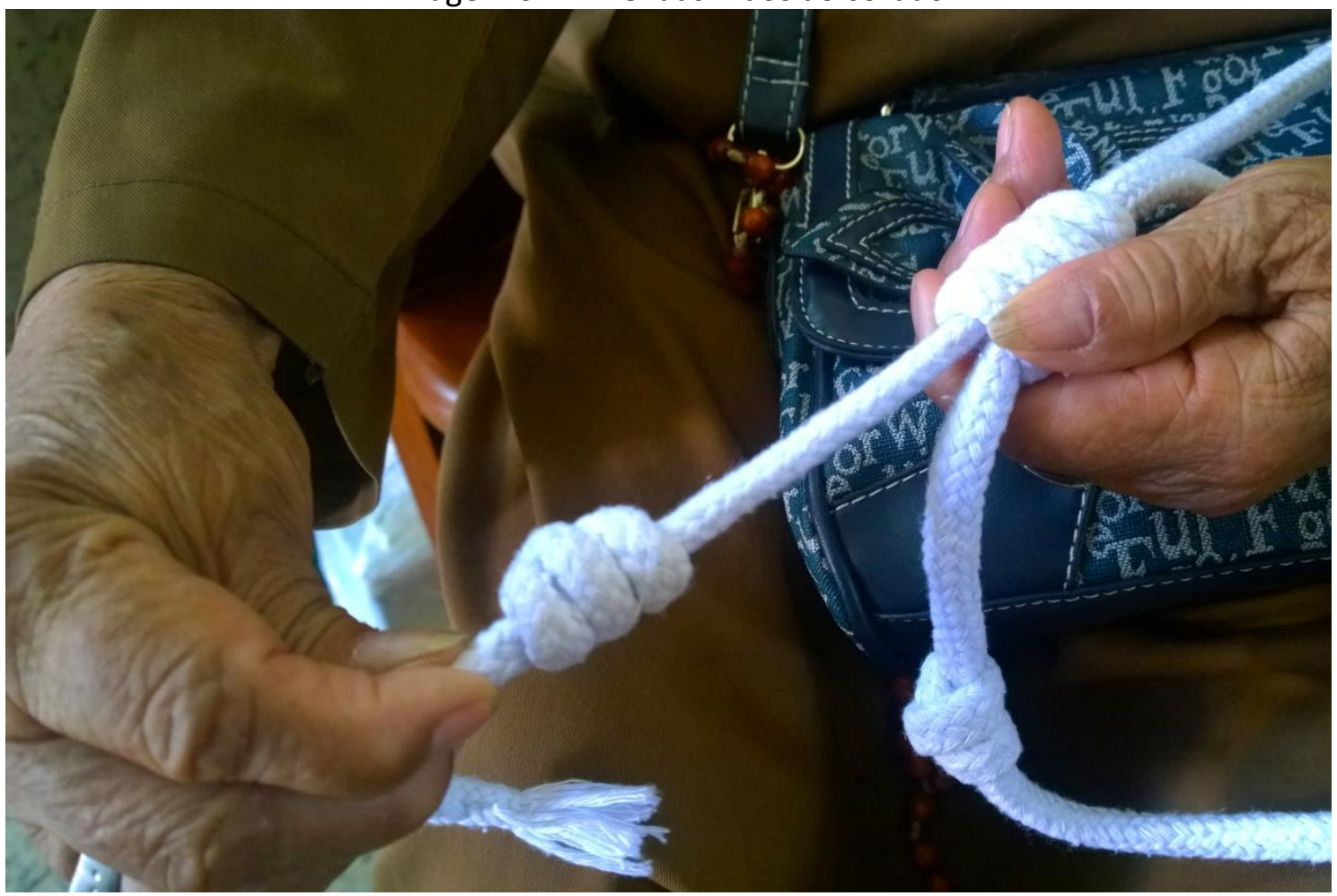


Imagem 05 - O descanso para prosseguir a romaria e os pedidos

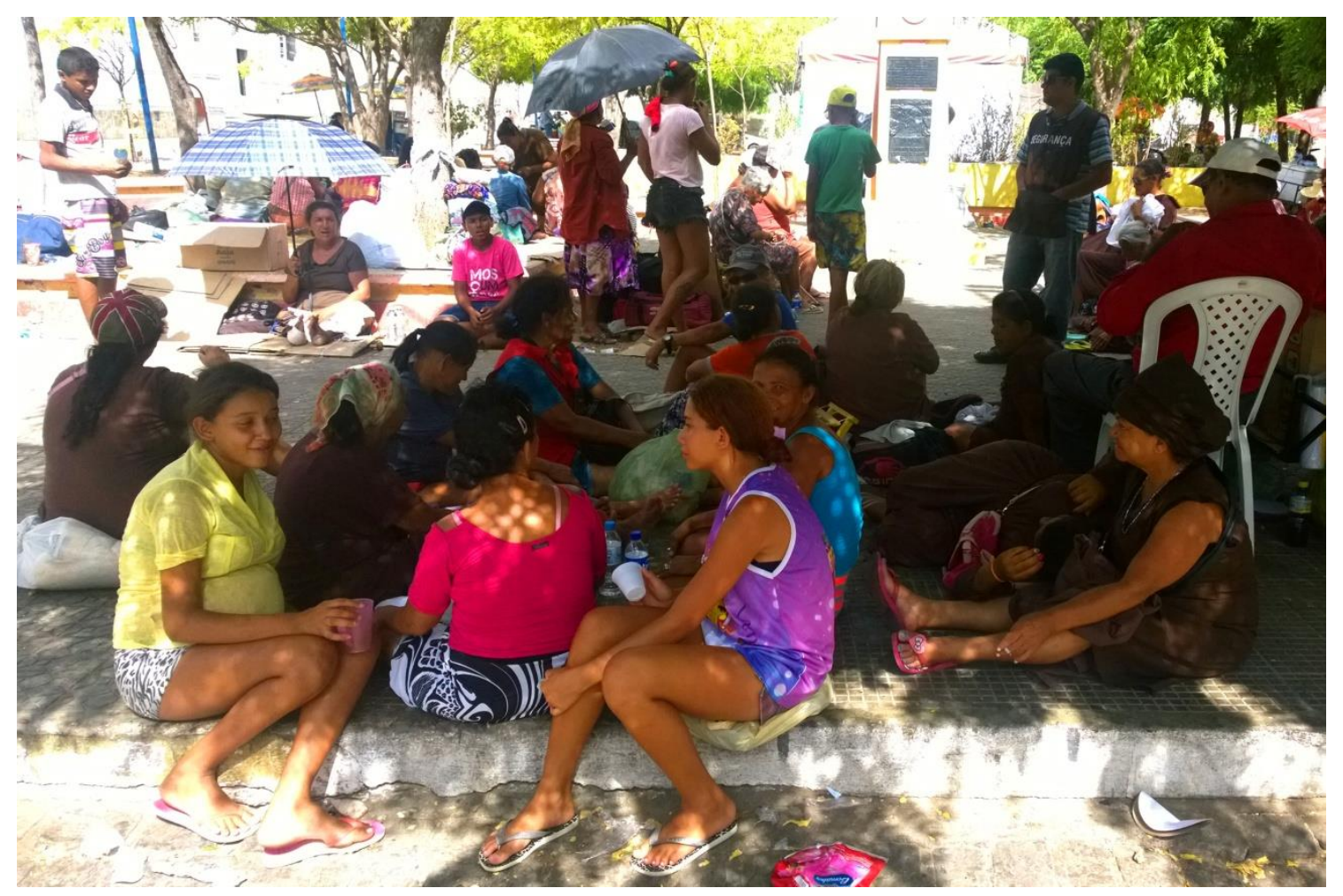

Imagem 06 - No rancho de apoio, a prece coletiva antes de prosseguir a romaria

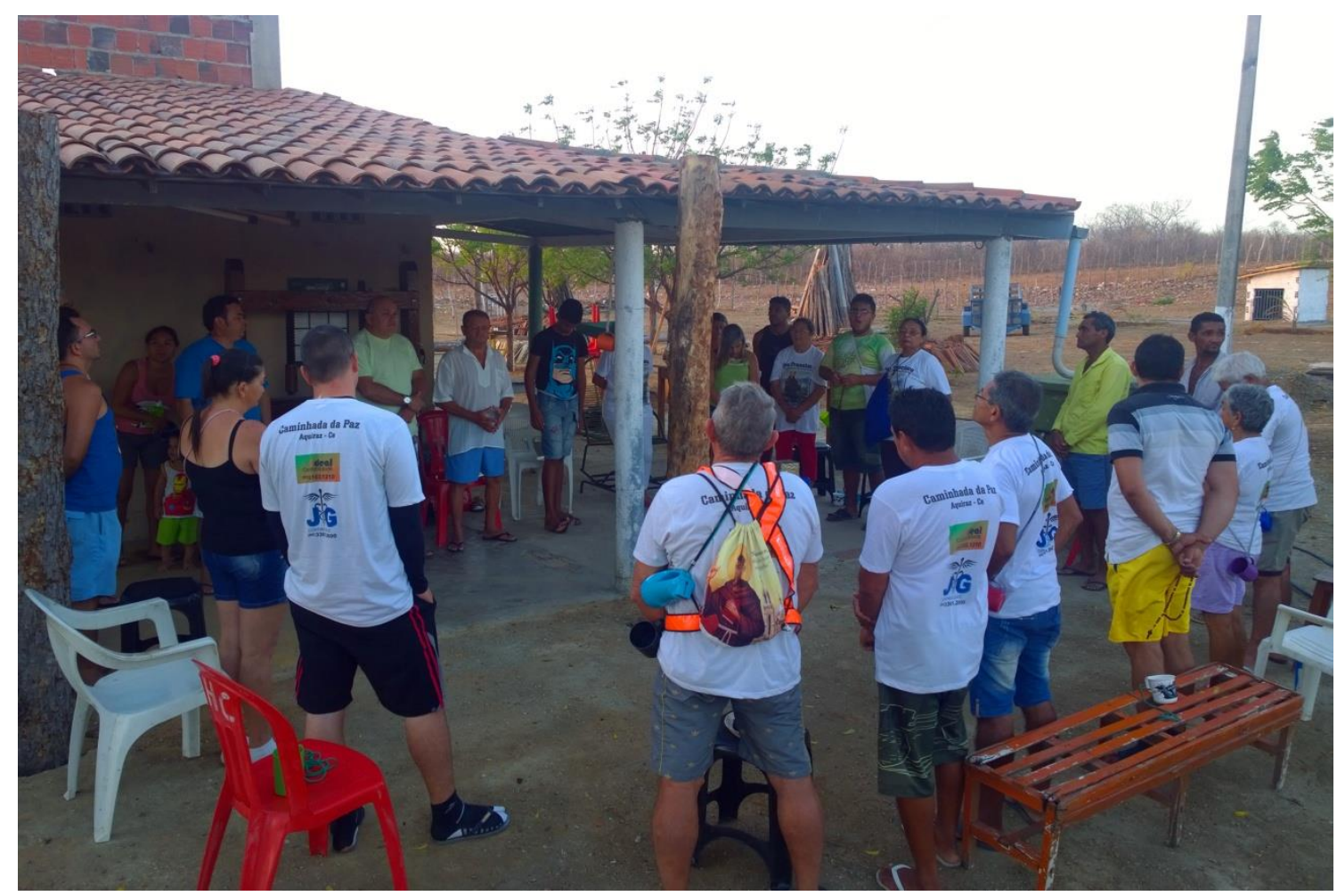


RIF, Ponta Grossa/ PR Volume 15, Número 34, p.239-248, Janeiro/Junho 2017

Imagem 07 - A oração pra Nosso Senhor dos Passos

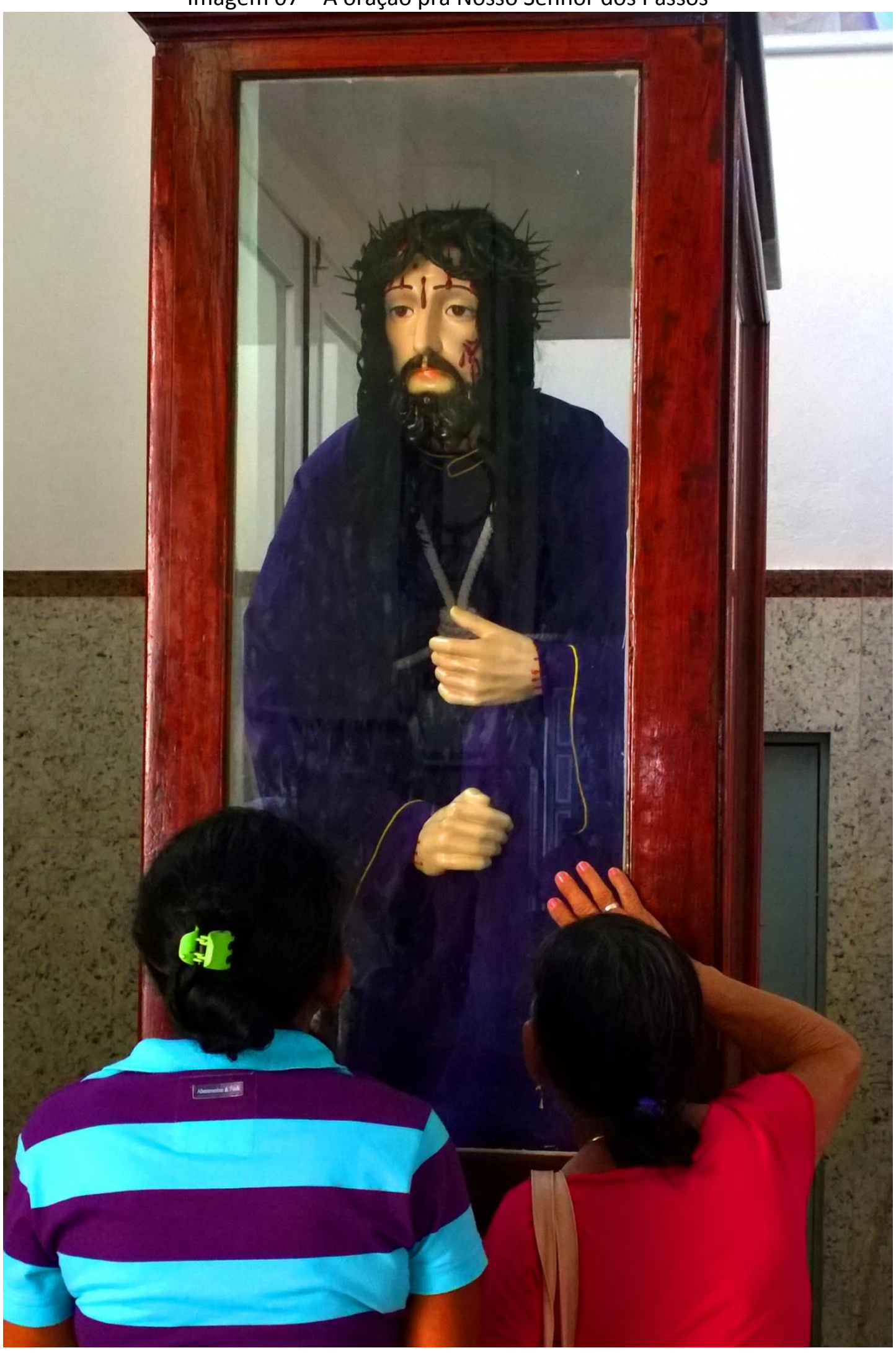

244 | Fé Canindé: sobre romeiros, romarias e ex-votos 
RIF, Ponta Grossa/ PR Volume 15, Número 34, p.239-248, Janeiro/Junho 2017

Imagem 08 - Octagenária maranhense e a fé traduzida nas romarias por quase toda a vida

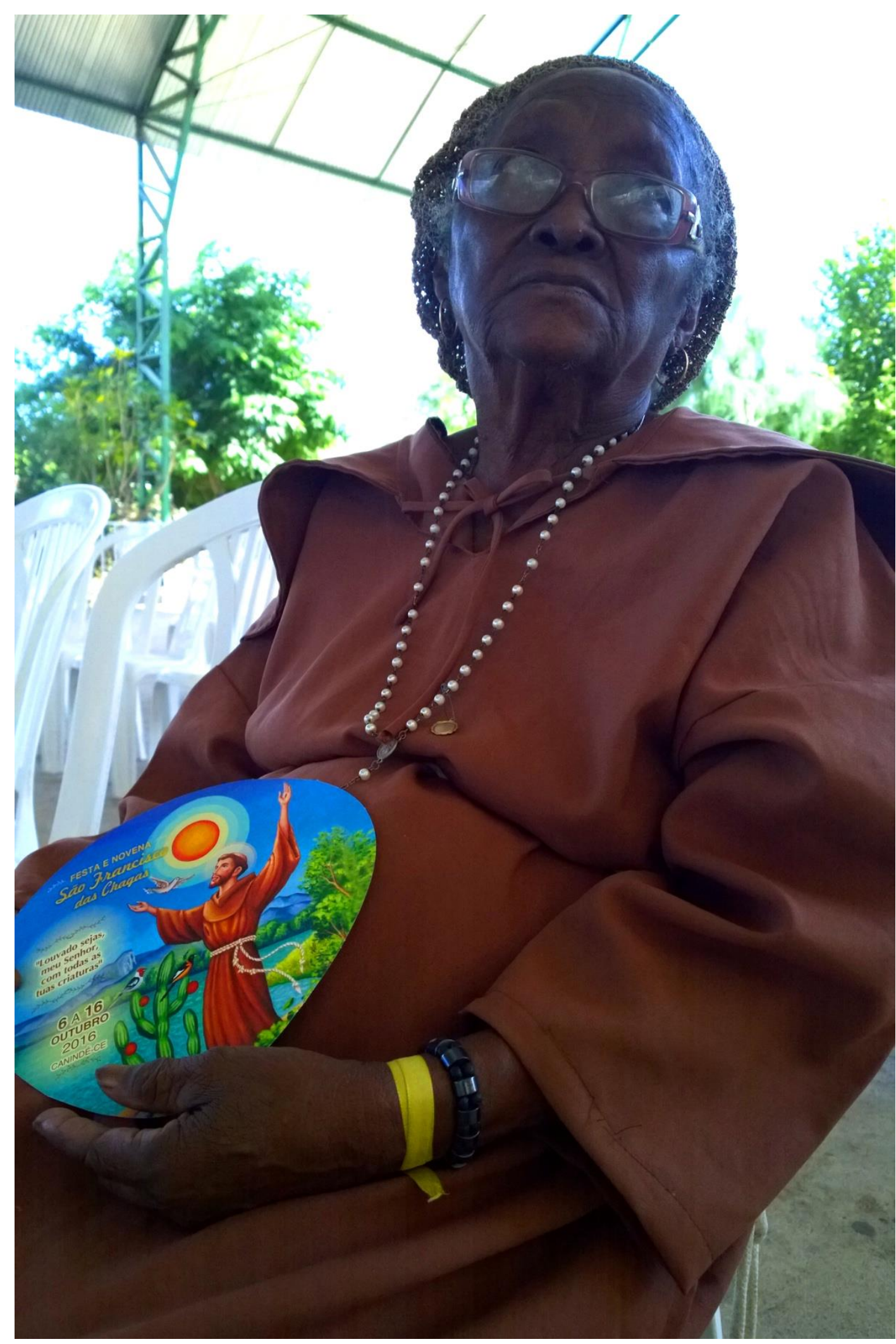

245 Fé Canindé: sobre romeiros, romarias e ex-votos 
Imagem 09- No painel a fé estampada nos ex-votos

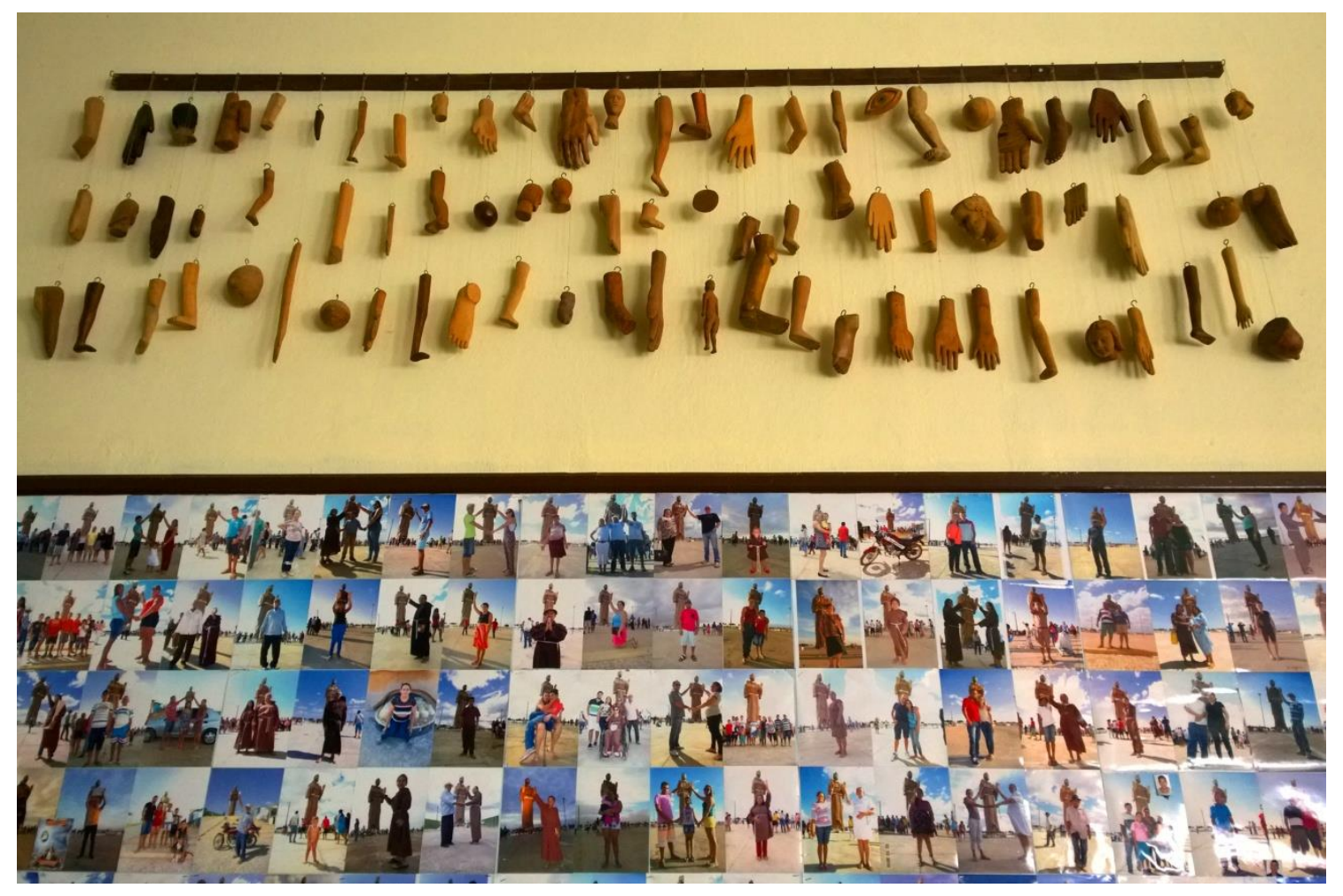


RIF, Ponta Grossa/ PR Volume 15, Número 34, p.239-248, Janeiro/Junho 2017

Imagem 10 - A entrada na igreja de joelhos é uma das formas de pagar a promessa

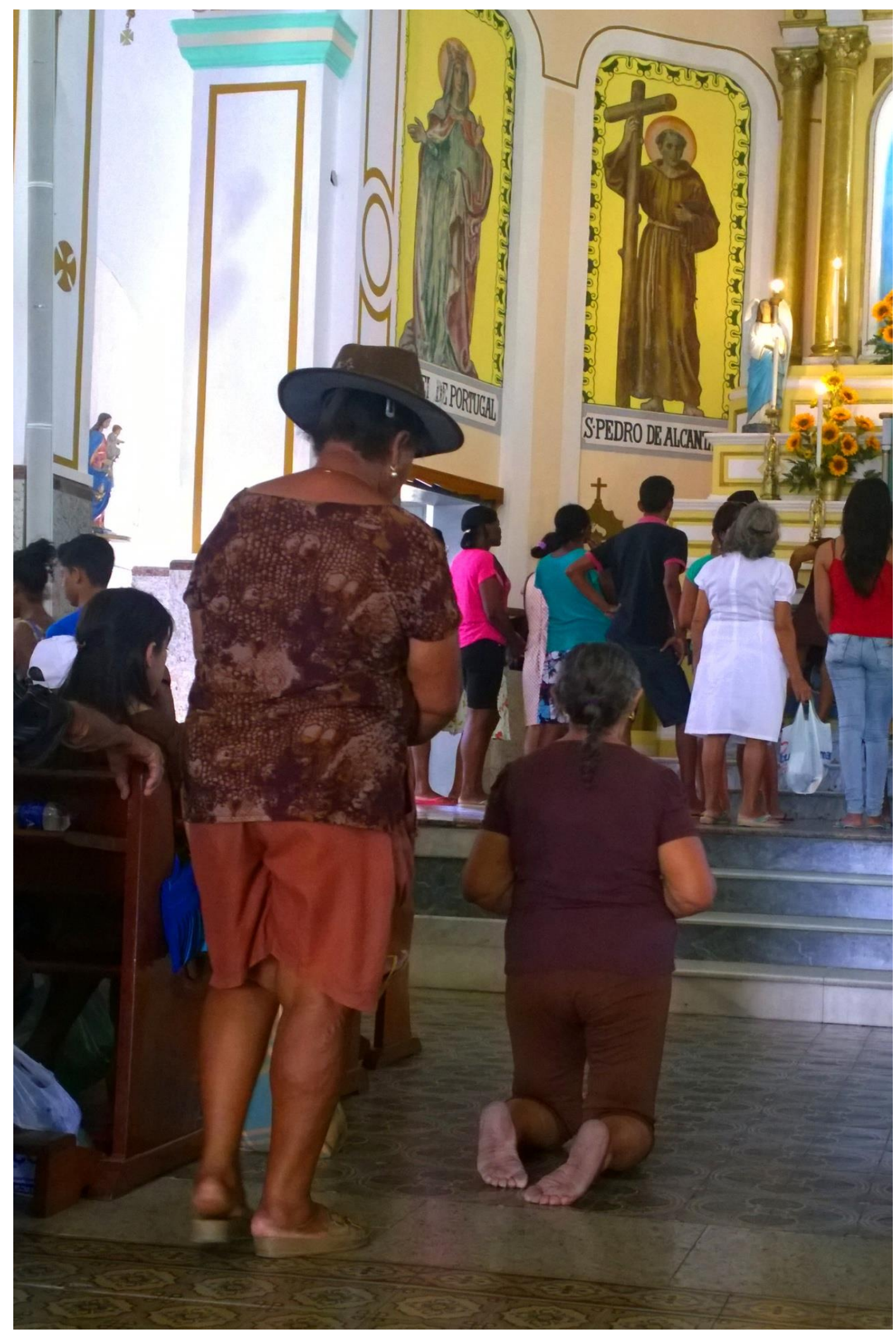

247 | Fé Canindé: sobre romeiros, romarias e ex-votos 
RIF, Ponta Grossa/ PR Volume 15, Número 34, p.239-248, Janeiro/Junho 2017

\section{Referências}

BELTRÃO, Luiz. Folkcomunicação: A comunicação dos marginalizados. São Paulo: Cortez, 1980.

CASCUDO, Luís da Câmara. Dicionário do folclore brasileiro. 10. ed. São Paulo: Global, 2001. $768 \mathrm{p}$.

NOBRE, Itamar de Morais. Revelando os modos de vida da ponta do Tubarão: A

fotocartografia sociocultural como uma proposta metodológica. EDUFRN: Natal, 2011. 